\title{
Research Paper: Lower Extremity Risk Factors in Iranian Adolescent Taekwondo Players
}

\author{
Mostafa Zarei ${ }^{1 *}$, Kamran Johari² Q , Rahim Bagherian ${ }^{3} \mathrm{Q}$ \\ 1. Sports Rehabilitation and Health Department, Faculty of Sports Sciences, Shahid Beheshti University, Tehran, Iran. \\ 2. Department of Sports Sciences, Islamic Azad University, Bukan Branch, West Azerbaijan, Bukan, Iran. \\ 3. Department of Sports Sciences, Islamic Azad University, Karaj Branch, Karaj, Iran.
}

\begin{tabular}{|c|c|}
\hline $\begin{array}{l}\text { Use your device to scan } \\
\text { and read the article online }\end{array}$ & \\
\hline 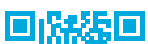 & Citation Zarei M, Johari K, Bagherian R. Lower Extremity Risk Factors in Iranian Adolescent Taekwondo Players. Physical \\
\hline riptiris & \\
\hline I:F4his & d of http://dx.doi.org/10.32598/ptj.10.1.403.1 \\
\hline
\end{tabular}

\section{(ब) 03}

Article info:

Received: 10 Jul 2019

Accepted: 22 Nov 2019

Available Online: 01 Jan 2020

Keywords:

Risk factor, Injury, Lower limb, Lower extremity alignment, Taekwondo player

\begin{abstract}
A B S T R A C T
Purpose: Taekwondo is a martial art and contact sport in which the athletes' goal is to strike the opponent with maximal force. This fact exposes taekwondo practitioners to the permanent risk of injuries. Therefore, the current prospective study aimed to investigate the internal risk factors of lower extremity injuries in the adolescent male taekwondo players.
\end{abstract}

Methods: In total, 60 adolescent taekwondo players of Iran Premier League voluntarily participated in this research. Before league commencement, navicular drop, Q angle, knee hyperextension angle, the dorsiflexion/plantarflexion range of motion, hamstring flexibility, and their dynamic balance were measured. Then, the injuries of these taekwondo players were recorded during the study time.

Results: The injury incidence rate was 7.9 per 1000 hours of exposure $(95 \%$ confidence interval, 5.33-10.40). The logistic regression analysis data indicated a significant relationship between the $\mathrm{Q}$ angle and injuries incidence rate (odds ratio $=1.33, \mathrm{P}=0.031$ ). The taekwondo players whose $\mathrm{Q}$ angles were $>14.5$ degrees were 1.33 times more prone to lower limb injury. However, no significant relationship was observed between the other risk factors of the study cases and injuries incidence.

Conclusion: Regarding the research findings, the $\mathrm{Q}$ angle could predict lower limb injuries in the studied taekwondo players. Therefore, it is suggested that this index be considered in the preparticipation evaluation process and preventive strategies.

\footnotetext{
* Corresponding Author:

Mostafa Zarei, PhD.

Address: Sports Rehabilitation and Health Department, Faculty of Sports Sciences, Shahid Beheshti University, Tehran, Iran.

Phone: +98 (913) 2615259

E-mail:m_zareei@sbu.ac.ir
} 


\section{Highlights}

- Taekwondo players with large Q angles may be at more significant risks for lower extremity injury.

- There was no association between navicular drop, knee hyperextension angle, dorsiflexion/plantarflexion range of motion, hamstring flexibility, and dynamic balance of adolescent taekwondo players and lower extremity injuries.

\section{Plain Language Summary}

Taekwondo is a martial art and contact sport in which the athletes' goal is to strike the opponent with maximal force. Thus, musculoskeletal injuries are common in its training and matches; however, little is known about its associated risk factors. The present study investigated risk factors for injuries among adolescent male taekwondo players. For this purpose, 60 taekwondo players from the Premier League participated in this study. All study subjects were evaluated prior to the onset of training. Navicular drop, quadriceps angle, body mass index, and hamstring flexibility of the samples were prospectively measured. Musculoskeletal injuries resulting from a 3-month season was recorded.These findings indicated that multiple anatomic measures, like the $\mathrm{Q}$ angle, can predict taekwondo risk factors for musculoskeletal injuries. Therefore, it's recommended that these indicators be evaluated before the taekwondo match season is started.

\section{Introduction}

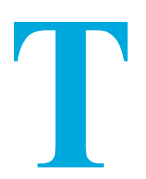

aekwondo, Tae Kwon Do, or Taekwon-Do is a Korean martial art, characterized by its emphasis on head-height kicks, jumping and spinning kicks, as well as fast kicking techniques. Taekwondo is among the professional sports in 140 countries, and 120 countries are officially members of the World Taekwondo Federation (WTF) [1]. Iran's taekwondo team is currently recognized among the world's top two powers.

Despite all the benefits of regular exercise, the risk of injury, especially in martial arts, is undeniable. The issue of sports injuries has become a matter of concern for athletes, coaches, and sports officials [2]. Altarriba-Bartes et al. reported a prevalence of 43 injuries per 1000 athletes and 7 injuries per 1000 minutes of fighting in the 20082016 Olympics [3].

Soon et al. also reported 38 injuries per 1000 athlete exposed among Korean taekwondo players [4]. Peter et al. reported an injury rate of $39.5 \%$ per athlete in European taekwondo players [5]. Rahnama et al. examined the prevalence, type, and mechanism of injury to young male taekwondo players in the national team; they reported that 27 out of 100 taekwondo players were injured and the rate of lower extremity injuries (60.5\%) was significantly higher than that of the other joints [2].

Ziaee et al. also examined the prevalence, location, type, causes, and mechanism of injury to Iranian elite taekwondo players. They stated that in the total 797 games played, 137 injuries occurred, and the prevalence rate of injury was 6.28 injuries per 100 match minutes [6]. Park et al. reported during a 10-year study of Korean elite taekwondo injuries; each athlete suffered 4.6 injuries per year [7]. Therefore, considering the high incidence of taekwondo injuries, it is essential to increase the safety and health of the taekwondo players to improve their safety and prevent costs.

It is vital to establish injury prevention programs to identify risk factors associated with the injury [8]. Some of the internal risk factors for lower extremity injuries include previous injury, age, flexibility, muscle strength, or muscle imbalance [8]. Fortina et al. reported the late onset of taekwondo exercise and the number of training sessions per week as risk factors for taekwondo injury. However, the results of studies on the relationship between risk factors and injury incidence are inconsistent. Some researchers have cited lower limb alignment as a risk factor for sports injuries.

For example, Van et al. studied 124 marathon runners in a 12-month study and their relationship to overuse injuries [9]. Researchers found a significant association between right foot arch height and shin splint injury, left foot arch height and hamstring injuries, heel valgus and back injuries, Q angle and ankle injuries, knee valgus and hip joint injuries, and leg length discrepancy and back, as well as ankle and foot injuries [10]. Hertel et al. reported increased navicular drop and pelvic tilt as an effective predictor of anterior cruciate ligament injury [8]. 
On the other hand, some researchers reported no relationship between the lower limb alignment and injury to athletes. For example, Soderman et al. investigated risk factors for lower extremity injuries in women football players; they stated no relationship between Q angle increase and injury incidence [11]. Pefanis et al. reported no significant relationship between ankle sprain injury and Q angle in volleyball, basketball, and soccer athletes [10].

Most taekwondo injuries occur in the lower extremities [7]. There is an inconsistency between the research results in this area. Moreover, controlling and preventing sports injuries is of importance. Thus, this study aimed to determine the relationship between lower extremity risk factors and injury incidence in adolescent taekwondo players.

\section{Materials and Methods}

The present study subjects were 60 adolescent male taekwondo players who participated in the 2018 adolescence Taekwondo National League Championships in Iran. All subjects' age range was 14-17 years. Moreover, they joined three weekly sessions of taekwondo training of the club team. The study subjects voluntarily participated in this study. None of the subjects had a history of severe lower extremity injury in the past year (injury causing $>28$ days of training and competition absenteeism).

To conduct this research, all the teams participating in the Iranian adolescent league competitions were invited by the Taekwondo Federation of Iran to participate in this research. The researcher explained the purposes and process of the research to all relevant instructors and supervisors. A day before conducting the tests, a summary of the research was described for the study samples. The study subjects then provided consent forms and their demographic information.

Before conducting the tests, all study subjects performed warm-up exercises for 5-10 minutes. Then, we evaluated their height, weight, leg length, Navicular drop, Q angle, knee hypertension angle, ankle plantar and dorsiflexion range of motion, dynamic balance, and Single-leg Triple Hop (SLTH), respectively. All tests were performed in a single session, and the timing, order of tests, and rest were the same for all study participants. All tests were performed by the researcher. Five minutes of rest was given for each test.

All taekwondo training activities and competitions from August 2018 to November 2018 were recorded daily in a particular form [12] by team coaches, and the relevant data were collected weekly by the researcher.
Teams' medical staff also recorded taekwondo injuries [12]. In this study, we recorded injuries that occurred during matches or training sessions, preventing the injured taekwondo player from participating in the team's next training session (at least 24 hours) in the following day (the definition of injury based on absences) [12].

The navicular drop was measured by the Brody technique. Accordingly, the subject was initially requested to sit on a chair with his hip and knee flexed at 90 degrees, feet on the floor, and subtalar joint in a neutral position, and without weight-bearing. The examiner touched the bone of the test navicular and measured its distance to the ground with a ruler. The study subject was then requested to stand upright and shoulder-width apart, and place the body weight evenly on two legs in a weightbearing position. The distance of the navicular to the ground was measured again. The difference between these two conditions was recorded in millimeters, as the amount of navicular drop. Measurement was performed on the preferred leg of the study subjects

To measure the $\mathrm{Q}$ angle, a line was drawn from the anterior superior iliac spine to the center of the patella. Then, another line was drawn from the center of the patella and tibia; the angle between the two lines is called the "Q" angle (Figure 1) [13]. The knee joint hyperextension angle was measured as the angle created in the sagittal plane by the femur (from the central point of the greater trochanter to the central point of the lateral epicondyle) and the shank (from the most lateral point of the proximal joint line of the knee through the lateral malleolus) [13].

To measure the Range of Motion (ROM) of the ankle dorsiflexion, the subject was placed in a lying-down po-

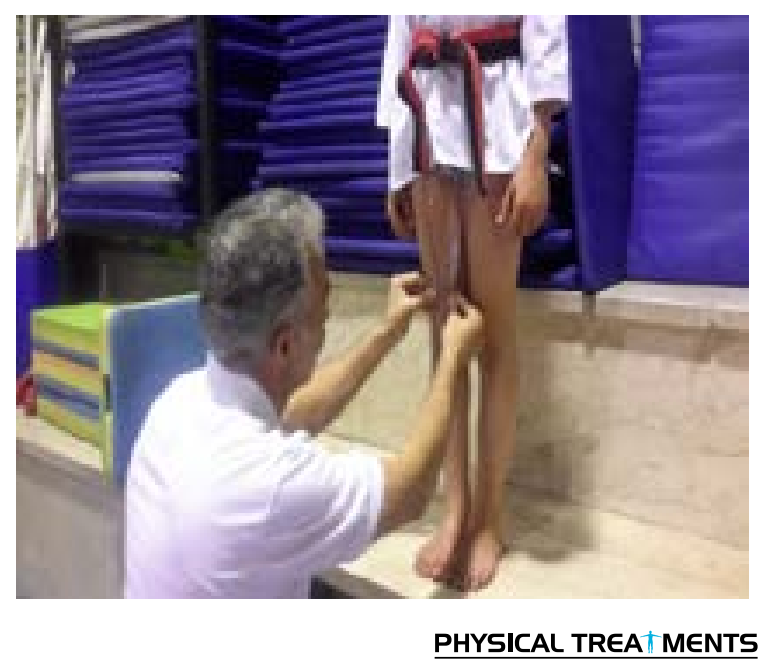

Figure 1. The measurement of the $Q$ angle 


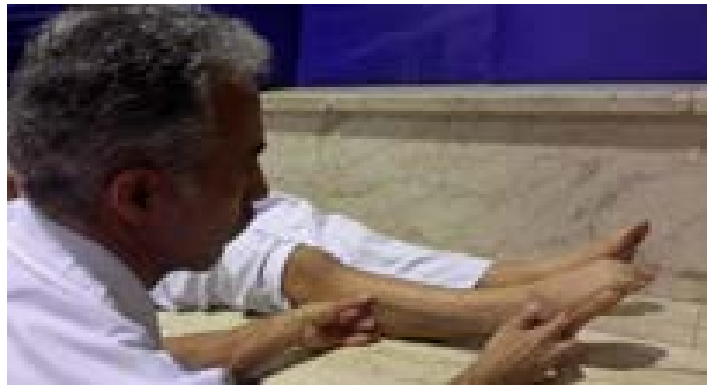

Figure 2. The measurement of ankle dorsiflexion ROM

sition, flexed the knee, and stabilized the sub-talar joint. Moreover, the examiner positioned the axis of goniometer on lateral calcaneus at the bisection of fibula + fifth metatarsal and stationary arm aligned with parallel to the fibula. The moving arm was aligned parallel with the fifth metatarsal. The study subject was requested to flex the dorsiflexion to the ankle and maintain the position at the end of the movement, and finally, the angle was recorded (Figure 2) [13].

The sit and reach test was used to measure the flexibility of the lumbar and posterior thigh muscles. This test was performed by a device manufactured by Iran Company. To perform this test, the person was first requested to sit on the floor with perfectly straight legs and knees, and with head and chest fully flat, and raise his hand as far as possible. Then, the marker was positioned close to the extender's fingers, and this point was considered to be zero. Next, the subject bent forward as far as possible without bending the knees and the trunk and by extending the posterior thigh muscles as far as possible. Slowest and highest marker displacement was recorded as the test score. The test was repeated twice, and the best result of each player was recorded [13].

In this study, the Y Balance Test (YBT) was used to evaluate dynamic postural control. The YBT is among the reliable and valid methods for assessing dynamic postural control. The test-retest and within-group reliability of this test were reported as favorable in healthy individuals [Intraclass Correlation Coefficient $($ ICC $)=0.98$ \& 0.91 , respectively] $[14,15]$.

To perform the Single-leg Triple Hop (SLTH) test, we fixed a standard cloth tape measure to the ground, perpendicular to a starting line. The study participants stood on the designated testing leg, with the great toe on the starting line. They performed 3 consecutive maximal hops forward on the same (dominant) limb. Arm swing was allowed. The investigator measured the distance

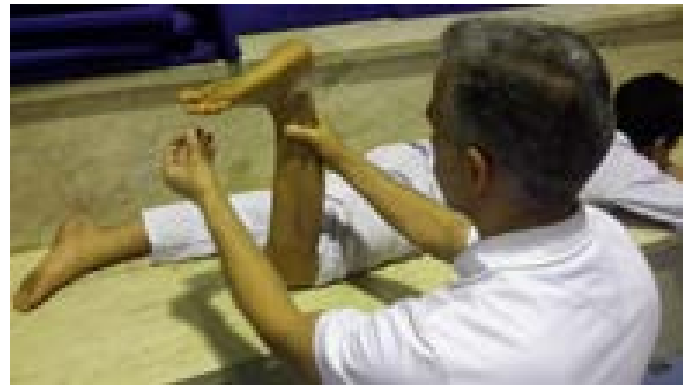

PHYSICAL TREATMENTS

hopped from the starting line to the point where the heel struck the ground upon completing the third hop

The limb symmetry index was used to calculate the index by dividing the maximum triple jump distance of the right leg by the maximum left triple jump distance and multiplying the number by 100 .

Logistic regression analysis was used to investigate the predictive relationship between risk factors indices and lower extremity injuries using SPSS.

\section{Results}

The demographic characteristics of the study subjects listed in Table 1.

In total, during the three-month study, 37 injuries were recorded. These injuries affected $28(46 \%)$ of the 60 taekwondo players. Additionally, during the study period, we recorded 4700 hours of taekwondo practice. This activity included 3200 hours with 1500 hours of training in the contest. The overall incidence of injury was 9.7 injuries per 1000 hours (95\% confidence interval, 5.33$10.40)$ and 7.10 injuries per 1000 hours of training (95\% confidence interval, 7.05-14.19), and 2 injuries per 1000 match hours (95\% confidence interval, 0.27-4.26). Knee joint with $38 \%$ and ankle with $32 \%$ rates were the most common sites of injury.

As per Table 2, there was only a significant predictive relationship between the $\mathrm{Q}$ angle of the adolescence taekwondo players and the occurrence of lower extremity injuries.

Figure 3 presents the Receiver Operating Characteristic (ROC) curve for the $\mathrm{Q}$ angle. The area underlying the ROC is 0.663 and $>0.5$, indicating a desirable performance of the $\mathrm{Q}$ angle index in predicting injuries. Based on the results of this curve, the value of $14.5 \mathrm{~cm}$ was considered as the cut-off point of the $\mathrm{Q}$ angle index. 
Table 1. The demographic characteristics of the study subjects

\begin{tabular}{cc}
\hline Variables & Mean \pm SD \\
\hline Age $(\mathrm{y})$ & $15.5 \pm .89$ \\
Height $(\mathrm{cm})$ & $175.25 \pm 8.05$ \\
Weight $(\mathrm{Kg})$ & $5.50 \pm 9.76$ \\
\hline Leg length $(\mathrm{cm})$ & $88.89 \pm 5.72$ \\
BMI $\left(\mathrm{kg} / \mathrm{m}^{2}\right)$ & $19.58 \pm 2.98$ \\
\hline
\end{tabular}

Table 2. Logistic regression analysis data for comparing the injured and non-injured taekwondo players

\begin{tabular}{|c|c|c|c|c|c|c|c|}
\hline \multirow{2}{*}{ Variables } & \multicolumn{2}{|c|}{ Mean $\pm S D$} & \multirow{2}{*}{ OR } & \multicolumn{2}{|c|}{ OR 95\% Confidence Interval } & \multirow{2}{*}{ Standard Error } & \multirow{2}{*}{$\mathbf{P}$} \\
\hline & $\begin{array}{c}\text { Non-injured Grupe } \\
\quad(n=32)\end{array}$ & $\begin{array}{l}\text { Injured Grupe } \\
\qquad(n=28)\end{array}$ & & Lower & Upper & & \\
\hline Navicular drop (mm) & $3.34 \pm 1.53$ & $3.46 \pm 1.81$ & 1.6 & 0.33 & 0.63 & 0.77 & 0.84 \\
\hline $\mathrm{Q}$ angle (degree) & $13.21 \pm 2.53$ & $14.71 \pm 2.85$ & 1.33 & 0.53 & 0.80 & 0.07 & $0.03 *$ \\
\hline $\begin{array}{l}\text { Hyperextension } \\
\text { (degree) }\end{array}$ & $0.56 \pm 0.25$ & $1.24 \pm 0.6$ & 2.16 & 0.26 & 0.55 & 0.07 & 0.23 \\
\hline $\begin{array}{l}\text { Dorsi flexion ROM } \\
\text { (degree) }\end{array}$ & $17.46 \pm 5.7$ & $15.74 \pm 4.85$ & 1.19 & 0.21 & 0.57 & 0.07 & 0.43 \\
\hline $\begin{array}{l}\text { Plantar flexion ROM } \\
\text { (degree) }\end{array}$ & $47.40 \pm 6.36$ & $46.6 \pm 7.00$ & 1.38 & 0.36 & 0.67 & 0.08 & 0.81 \\
\hline Sit and Reach $(\mathrm{cm})$ & $37.00 \pm 7.74$ & $37.10 \pm 8.4$ & 1.11 & 0.38 & 0.68 & 0.08 & 0.70 \\
\hline $\mathrm{YBT}$, anterior & $81.8 \pm 5.47$ & $81.29 \pm 7.09$ & 1.37 & 0.33 & 0.64 & 0.07 & 0.88 \\
\hline YBT, Posteromedial & $122.80 \pm 9.91$ & $120.13 \pm 11.85$ & 1.59 & 0.30 & 0.60 & 0.07 & 0.51 \\
\hline YBT, Posterolateral & $110.91 \pm 10.36$ & $112.24 \pm 10.63$ & 1.38 & 0.38 & 0.67 & 0.07 & 0.70 \\
\hline YBT, Composite & $105.18 \pm 7.0$ & $104.6 \pm 9.18$ & 1.13 & 0.34 & 0.65 & 0.07 & 0.97 \\
\hline SLTH (cm) & $539.32 \pm 72.64$ & $544.09 \pm 77.38$ & 1.18 & 0.37 & 0.64 & 0.07 & 0.75 \\
\hline
\end{tabular}

*Significant at $\mathrm{P}<0.05$.

PHYSICAL TREA $\pitchfork$ MENTS

\section{Discussion}

The present study results suggested a significant relationship between the navicular drop of the preferred leg, knee hyper-extension angle, dorsiflexion and plantarflexion ROM, and the flexibility of the posterior thigh muscles of adolescent taekwondo players and their lower extremity injuries. These findings are in line with those of Michelson et al. (2003); they investigated the relationship between flat foot and risk of injury in athletes and detected no association between the flat foot and lower extremity injuries.

On the other hand, the present study data are inconsistent with those of the studies by Tong and Kong (2013) [16], Butler (2006) [17], Kennedy et al. (2005), Zarei
(2014) [18], Letafatkar et al. (2013) [19], and Saki (2009) [20]. Tong and Kong (2013), in a systematic review, surveyed the relationship between foot arch structure and injury incidence using the meta-analysis method. They examined 29 studies and reported a significant correlation between decreased arches and lower extremity injuries [16]. Zarei (2014) investigated the relationship between static lower limb alignment and injuries in youth soccer players. They concluded that smaller limb alignment measurements, such as Q angle, knee valgus, and navicular drop, could identify players at risk of lower limb injuries [18].

Furthermore, in a prospective study, Michelle et al. (2016) examined the association between hamstring flexibility and its injuries in 450 amateur football play- 


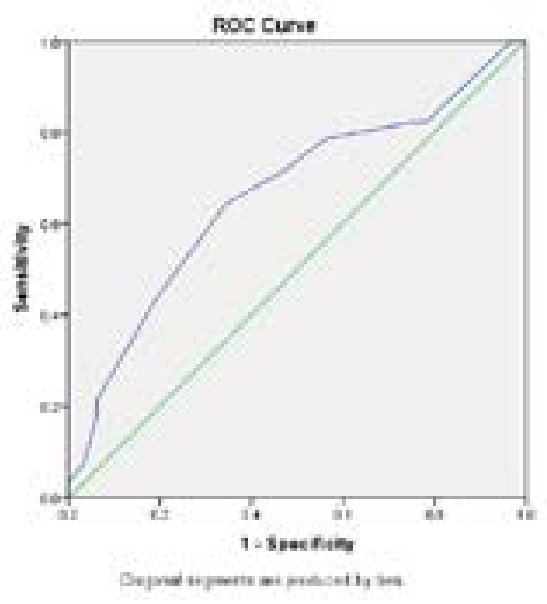

PHYSICAL TREA $\mid$ MENTS

Figure 3. ROC curve for the $Q$ angle

ers. In this study, sit and reach test was used to measure hamstring flexibility. The relevant findings revealed no significant relationship between hamstring flexibility and non-contact injuries to soccer players. Faskis et al. (2012) examined the internal risk factors of ankle sprain in 100 football players and observed no relation between flexibility and non-contact lower extremity injuries. Arnason et al. (2004) explored the injuries of 306 male football players; they concluded that flexibility, strength, vertical jump, and joint instability did not affect injury [21].

In a prospective study, Neilsted et al. (2014) assessed the risk factors of lower extremity injuries in female soccer players and concluded that balance had no significant relationship with lower extremity injuries. In addition, Acne et al. (2014) investigated the risk factors of lower extremity injuries in elite female footballers and stated that dynamic balance was not related to lower extremity injuries. Williams (2013) also found no predictive relationship between injury and dynamic balance performance in male and female marathon runners [22].

The reason for the inconsistency of the research mentioned above with the present study may be the difference, like the mentioned sports with taekwondo, the gender differences, and the heterogeneity of the studied subjects' age.

The obtained data highlighted a significant relationship between the Q angle of the investigated adolescent taekwondo players and their lower extremity injuries. These results are in line with those of Zarei (2014) [18], Letafatkar et al. (2013) [19], Pokri et al. (2007) [23], and Chaudhari et al. (2003). Zarei (2014) studied the relationship between static lower limb alignment and inju- ries to young football players. They reported a significant association between Q angle and lower extremity injuries [18]. Moreover, Pokéri (2009) studied endurance runners' Q angle and knee injury; they argued that runners with an abnormal Q angle were more prone to injuries. Researchers have documented that the knee varus/valgus angle affects the biomechanics of the lower extremity joints. The varus/valgus normal alignment could affect the impact force on the lower extremity joints, and the force-torque applied to the knee when the foot impacts the ground [9].

However, the current research results are inconsistent with those of Lun et al. (2004) [24] and Sooderman et al. (2001) [11]. Lun et al. (2004) detected no relationship between lower extremity alignment and injuries in amateur runners [24]. Additionally, Sooderman et al. (2001), in a prospective study on female soccer players, reported $Q$ angle was not a risk factor for lower extremity injury [11]. There are many reasons for the inconsistency of the present study data with those of the research mentioned above, most notably, the differences in the type of exercise, gender, and volume of subjects.

Plisky et al. (2006) stated that basketball players whose overall score on the YBT was $<94 \%$ were 6 times more likely than other players to experience lower extremity injuries [25]. Butler et al. (2013) also examined dynamic balance performance and lower extremity injuries in $59 \mathrm{col}-$ lege football players. They found that players who scored $<89.6 \%$ in the YBT were 3.5 times more prone to injuries than the other players [17]. It seems that the sample size, gender, and age of the investigated subjects are inconsistent with those of the two mentioned studies; therefore, more careful consideration is needed in this area [22].

One of the most critical limitations of this study was the short follow-up time. Since the taekwondo season lasts three months, athletes were investigated in terms of injury during this time. Another limitation of this study was its relatively small sample size, which should be considered in generalizing the results. Thus, it is recommended that similar studies be conducted with longer follow-up periods and larger sample sizes.

\section{Conclusion}

According to the present study findings, the $\mathrm{Q}$ angle could predict lower extremity injuries in taekwondo players. Thus, taekwondo coaches and trainers could use the $\mathrm{Q}$ angle test as a valid simple tool to identify at-risk players before competitions begin. Therefore, it is recommended that pre-season assessments of this index be 
taken into consideration by medical staff and taekwondo coaches. Besides, injury prevention programs should be considered for athletes when increased.

\section{Ethical Considerations}

\section{Compliance with ethical guidelines}

The study was approved by the local ethics committee of Islamic Azad University, Karaj Branch.

\section{Funding}

The present paper was extracted from the MSc thesis of the third author, Department of Sports Sciences, Islamic Azad University, Karaj Branch.

\section{Authors' contributions}

Conceptualization, investigation: Mostafa Zarei, Kamran Johari, Rahim Bagherian; Methodology, funding acquisition: Mostafa Zarei, Rahim Bagherian; Writing - original draft: Kamran Johari, Rahim Bagherian; Writing - review \& editing, supervision: Mostafa Zarei, Kamran Johari.

\section{Conflict of interest}

The authors declared no conflict of interests.

\section{References}

[1] Kazemi M, Waalen J, Morgan C, White AR. A profile of Olympic taekwondo competitors. Journal of Sports Science \& Medicine. 2006; 5(CSSI):114-21.

[2] Rahnama N, Namazi-Zadeh M, Bambaihi E, Sadeghipour HR, Taqavi A. [Prevalence, type and mechanism of injuries of adolescent male taekwondo (Persian)]. Olympic Journal. 2007; 15(4):115-24

[3] Lystad RP, Soligard T, Engebretsen L, editors. Epidemiology of Taekwondo Injuries in the Olympic Games. The 6th International Symposium for Taekwondo Studies. 2017; 17:49-50.

[4] Son BA, Jeong HS, Kong ID, Lee SY. Epidemiological study of taekwondo injuries: 1-year prospective study. British Journal of Sports Medicine. 2017; 51(4):391-2. [DOI:10.1136/ bjsports-2016-097372.273]

[5] Pieter W, Lufting R. Injuries at the 1991 taekwondo world championships. Journal of Sports Traumatology and Related Research. 1994; 16(1):49-56.

[6] Ziaee V, Rahmani SH, Rostami M. Injury rates in Iranian taekwondo athletes; A prospective study. Asian Journal of Sports Medicine. 2010; 1(1):23.
[7] Park KJ, Song BB. Injuries in female and male elite taekwondo athletes: A 10-year prospective, epidemiological study of 1466 injuries sustained during 250000 training hours. British Journal of Sports Medicine. 2018; 52(11):735-40. [DOI:10.1136/bjsports-2017-097530] [PMID]

[8] Hertel J, Dorfman JH, Braham RA. Lower extremity malalignments and anterior cruciate ligament injury history. Journal of Sports Science \& Medicine. 2004; 3(4):220-5.

[9] Wen DY, Puffer JC, Schmalzried TP. Lower extremity alignment and risk of overuse injuries in runners. Medicine and Science in Sports and Exercise. 1997; 29(10):1291-8. [DOI:10.1097/00005768-199710000-00003] [PMID]

[10] Pefanis N, Papaharalampous X, Tsiganos G, Papadakou E, Baltopoulos P. The effect of $Q$ angle on ankle sprain occurrence. Foot \& Ankle Specialist. 2009; 2(1):22-6. [DOI:10.1177/1938640008330769] [PMID]

[11] Söderman K, Alfredson H, Pietilä T, Werner S. Risk factors for leg injuries in female soccer players: A prospective investigation during one out-door season. Knee Surgery, Sports Traumatology, Arthroscopy. 2001; 9(5):313-21. [DOI:10.1007/s001670100228] [PMID]

[12] Fuller CW, Ekstrand J, Junge A, Andersen TE, Bahr R, Dvorak J, et al. Consensus statement on injury definitions and data collection procedures in studies of football (soccer) injuries. Scandinavian Journal of Medicine \& Science in Sports. 2006; 16(2):83-92. [DOI:10.1111/j.16000838.2006.00528.x] [PMID]

[13] Rajabi R, Samadi H. [Corrective exercise Laboratory (Persian)]. Tehran: Tehran University Press Institute; 2014.

[14] Plisky PJ, Gorman PP, Butler RJ, Kiesel KB, Underwood FB, Elkins $B$. The reliability of an instrumented device for measuring components of the star excursion balance test. North American journal of Sports Physical Therapy: NAJSPT. 2009; 4(2):92-9.

[15] Clark RC, Saxion CE, Cameron KL, Gerber JP. Associations between three clinical assessment tools for postural stability. North American Journal of Sports Physical Therapy: NAJSPT. 2010; 5(3):122-30.

[16] Tong JW, Kong PW. Association between foot type and lower extremity injuries: Systematic literature review with metaanalysis. Journal of Orthopaedic \& Sports Physical Therapy. 2013; 43(10):700-14. [DOI:10.2519/jospt.2013.4225] [PMID]

[17] Butler RJ, Lehr ME, Fink ML, Kiesel KB, Plisky PJ. Dynamic balance performance and noncontact lower extremity injury in college football players: An initial study. Sports Health. 2013; 5(5):417-22. [DOI:10.1177/1941738113498703] [PMID] [PMCID]

[18] Zarei M. The relationship between static lower limb alignment and injuries in youth soccer players. Sports Medicine and Technology. 2016; 14(12):59-70. [DOI:10.18869/acadpub.jsmt.14.12.59]

[19] Letafatkar A, Zandi S, Khodayi M, Vashmesara JB. Flat foot deformity, Q Angle and knee Pain are interrelated in wrestlers. Journal of Novel Physiotherapies. 2013; 3:138. [DOI:10.4172/2165-7025.1000138]

[20] Saki F. [An Investigation of the Lower Limb of Athletes with Anterior cruciate Ligament Injury (Persian)] [MSc. Thesis]. Rasht: University of Guilan; 2009. 
[21] Arnason A, Andersen T, Holme I, Engebretsen L, Bahr R. Prevention of hamstring strains in elite soccer: an intervention study. Scandinavian Journal of Medicine \& Science in Sports. 2008; 18(1):40-8. [DOI:10.1111/j.16000838.2006.00634.x] [PMID]

[22] Williams III DS, McClay IS, Hamill J, Buchanan TS. Lower extremity kinematic and kinetic differences in runners with high and low arches. Journal of Applied Biomechanics. 2001; 17(2):153-63. [DOI:10.1123/jab.17.2.153]

[23] Puckree T, Govender A, Govender K, Naidoo P. The quadriceps angle and the incidence of knee injury in Indian longdistance runners. South African Journal of Sports Medicine. 2007; 19(1):9-11. [DOI:10.17159/2413-3108/2007/v19i1a269]

[24] Lun V, Meeuwisse W, Stergiou P, Stefanyshyn D. Relation between running injury and static lower limb alignment in recreational runners. British Journal of Sports Medicine. 2004 38(5):576-80. [DOI:10.1136/bjsm.2003.005488] [PMID] [PMCID]

[25] Plisky PJ, Rauh MJ, Kaminski TW, Underwood FB. Star Excursion Balance Test as a predictor of lower extremity injury in high school basketball players. Journal of Orthopaedic \& Sports Physical Therapy. 2006; 36(12):911-9. [DOI:10.2519/ jospt.2006.2244] [PMID] 